\title{
Role of pituitary tumour transforming gene 1 in medullary thyroid carcinoma
}

\author{
Maria Chiara Zatelli ${ }^{a}$, Federico Tagliati ${ }^{a}$, Vincenzo Amodio ${ }^{a}$, Mattia Buratto ${ }^{a}$, Mariarosa Pelizzo ${ }^{b}$, \\ Giancarlo Pansini ${ }^{\mathrm{c}}$, Marta Bondanelli ${ }^{\mathrm{a}}$, Maria Rosaria Ambrosio ${ }^{\mathrm{a}}$ and Ettore C. degli Uberti ${ }^{\mathrm{a}, *}$ \\ ${ }^{a}$ Section of Endocrinology, Department of Biomedical Sciences and Advanced Therapies, University of Ferrara, \\ Ferrara, Italy \\ ${ }^{\mathrm{b}}$ Department of Medical and Surgical Science, General Surgery III, University of Padua, Padua, Italy \\ ${ }^{\mathrm{c}}$ Section of General Surgery, Department of Surgery, University of Ferrara, Ferrara, Italy
}

\begin{abstract}
Background: Pituitary tumour transforming gene 1 (PTTG1) is over-expressed in a variety of endocrine-related tumours. We aimed at evaluating PTTGl expression and function in human neoplastic parafollicular C-cells, represented by medullary thyroid carcinoma (MTC) and C-cell hyperplasia (CCH) samples and by the TT cell line.

Methods: TT cells and tissues derived from human CCH ( 8 samples) and MTC (12 samples) were analyzed by northern blot, furthermore TT cells were subjected to $P T T G$ gene silencing and cells were analyzed for DNA synthesis.

Results: PTTG1 expression was significantly higher $(p<0.01)$ in $\mathrm{CCH}$ (3-fold), in papillary thyroid cancer and in MTC (5fold) than in normal thyroid, and in MTC lymph-node metastases as compared to primary lesions ( $\sim 2$-fold; $p<0.05$ ). PTTG1 mRNA and protein correlated with tumour diameter and TNM status $(p<0.05)$. In TT cells, PTTG1 silencing did not completely block DNA synthesis, but significantly reduced $\left[{ }^{3} \mathrm{H}\right]$ Thymidine incorporation $(\sim 50 \% ; p<0.01)$ for up to 3 days.

Conclusions: PTTG1 levels correlate with tumour aggressiveness. PTTG1 silencing causes reduced MTC cell proliferation, supporting the hypothesis that PTTG1 might have an important role in C-cell neoplastic proliferation.
\end{abstract}

Keywords: Pituitary tumour transforming gene 1, medullary thyroid carcinoma, TT cells, siRNA

\section{Introduction}

Pituitary tumour transforming gene 1 (PTTGl) is over-expressed in a variety of endocrine-related tumours, as well as non-endocrine cancers [15], where high PTTG1 expression correlates with a poor prognosis [22,30]. PTTG1 is a multifunctional human securin, involved in the control of mitosis [23,31], cell transformation $[8,29]$, DNA repair [16] and gene regulation $[13,14,29]$. PTTG1 also exhibits transactivational activity [21]. PTTG1 expression is higher in recurrent as compared to primary differentiated thyroid cancer [3], supporting the hypothesis that PTTG1 is important for thyroid cancer progression. On the other hand, PTTG1 overexpression in mouse NIH 3T3 fibroblasts inhibits cell proliferation and induces cell transforma-

\footnotetext{
* Corresponding author: Prof. Ettore C. degli Uberti, Section of Endocrinology, Department of Biomedical Sciences and Advanced Therapies, University of Ferrara, Via Savonarola 9, 44100 Ferrara, Italy. Tel.: +39 0532 236682; Fax: +39 0532 236514; E-mail: ti8@unife.it.
}

tion in vitro [15]. It has indeed been previously demonstrated that the multifunctional PTTGI-encoded protein, securin, markedly influences cell proliferation depending on its expression levels, suggesting that altered PTTGl expression may differentially affect cell turnover. In fact, low levels of PTTG1 expression stimulate cell proliferation, while at higher levels it inhibits cell turnover [4].

Involvement of PTTG1 in medullary thyroid carcinoma (MTC) has not thus far been tested. MTC, derived from parafollicular thyroid C-cells, accounts for $3-5 \%$ of cases of thyroid cancer $[5,18]$ and is characterized by early metastases and poor prognosis. Understanding molecular pathways involved in the control of MTC and C-cell hyperplasia (CCH) development is fundamental for applying novel therapies for patients with advanced MTC. Indeed, the majority of MTC patients have persistent or recurrent post-operative disease which is not amenable to medical therapy.

In the present study we investigated PTTG1 expression in human CCH, MTC and in the human MTC cell 
line, TT. Moreover, the role of PTTG1 in neoplastic C-cell proliferation was studied by modulating PTTG1 expression.

\section{Material and methods}

\subsection{Patients}

Samples were derived from 8 patients operated on for $\mathrm{CCH}, 12$ patients operated on for primary MTC, and 7 patients operated on for MTC neck lymphnode metastases, as confirmed by histology and immunohistochemistry. Tissues were harvested under sterile conditions, as previously described [28]. Surgical procedures were performed at the Section of
General Surgery of the University of Ferrara and at the Department of General Surgery of the University of Padova. Tissues derived from papillary thyroid carcinoma (PTC) samples were considered as positive controls. Tissues were microdissected as previously described [11]. Table 1 shows individual patient characteristics, including demographic details, tumour node metastasis (TNM), staging at surgery, Calcitonin (CALC) plasma levels and tumour size. Tumour size of 2 MTC patients was not available (\#22 and \#24). All patients (12 males and 15 females; aged $52.6 \pm$ 4.2 years) underwent total thyroidectomy with central neck lymph-node clearance. Patient informed consent was obtained for disclosing clinical investigation and performing the in vitro study that was approved by the local Ethical Committee.

Table 1

Characteristics of $\mathrm{CCH}$ and MTC patients

\begin{tabular}{|c|c|c|c|c|c|c|c|c|}
\hline No. & Age & Sex & Inheritance & TNM & STAGE & Plasma CALC (pg/ml) & Lesion type & Max diameter $(\mathrm{cm})$ \\
\hline 1 & 60 & $\mathrm{~F}$ & SP & - & - & 332 & $\mathrm{P}$ & - \\
\hline 2 & 10 & M & MEN 2A & - & - & 59 & $\mathrm{P}$ & - \\
\hline 3 & 11 & $\mathrm{~F}$ & MEN 2A & - & - & 84 & $\mathrm{P}$ & - \\
\hline 4 & 51 & M & SP & - & - & 93 & $\mathrm{P}$ & - \\
\hline 5 & 51 & M & SP & - & - & 157 & $\mathrm{P}$ & - \\
\hline 6 & 35 & M & SP & - & - & 68 & $\mathrm{P}$ & - \\
\hline 7 & 62 & $\mathrm{~F}$ & SP & - & - & 136 & $\mathrm{P}$ & - \\
\hline 8 & 12 & M & MEN 2A & - & - & 73 & $\mathrm{P}$ & - \\
\hline 9 & 69 & $\mathrm{~F}$ & SP & $\mathrm{T} 2 \mathrm{NxMx}$ & I & 410 & $\mathrm{P}$ & 0.7 \\
\hline 10 & 76 & $\mathrm{~F}$ & SP & T1N0Mx & II & 1500 & $\mathrm{P}$ & 3.9 \\
\hline 11 & 56 & $\mathrm{M}$ & SP & T1NxMx & I & 875 & $\mathrm{P}$ & 0.6 \\
\hline 12 & 69 & $\mathrm{~F}$ & SP & $\mathrm{T} 2 \mathrm{~N} 1 \mathrm{Mx}$ & III & 1950 & $\mathrm{P}$ & 2.2 \\
\hline 13 & 73 & $\mathrm{~F}$ & SP & T1N0Mx & I & 163 & $\mathrm{P}$ & 0.8 \\
\hline 14 & 18 & $\mathrm{~F}$ & MEN 2A & T1N0Mx & I & 69 & $\mathrm{P}$ & 1.8 \\
\hline 15 & 77 & F & SP & T1N0Mx & I & 217 & $\mathrm{P}$ & 3.4 \\
\hline 16 & 61 & M & SP & T3N0Mx & II & 2580 & $\mathrm{P}$ & 4.5 \\
\hline 17 & 38 & $\mathrm{~F}$ & SP & T2N0Mx & II & 2350 & $\mathrm{P}$ & 4.0 \\
\hline 18 & 53 & $\mathrm{~F}$ & SP & T2N0Mx & II & 306 & $\mathrm{P}$ & 1.6 \\
\hline 19 & 63 & $\mathrm{~F}$ & SP & T2N0Mx & II & 74.5 & $\mathrm{P}$ & 1.6 \\
\hline 20 & 27 & $\mathrm{~F}$ & MEN 2A & T2NxMx & II & 940 & $\mathrm{P}$ & 2.0 \\
\hline 21 & 66 & M & MEN 2A & TxN1Mx & III & 116.5 & $\mathrm{~L}$ & 1.0 \\
\hline 22 & 86 & $\mathrm{~F}$ & SP & TxN1Mx & III & 776 & $\mathrm{~L}$ & n.d. \\
\hline 23 & 67 & $\mathrm{M}$ & SP & TxN1Mx & III & 1530 & $\mathrm{~L}$ & 0.7 \\
\hline 24 & 71 & $\mathrm{~F}$ & SP & TxN1Mx & IV & 140 & $\mathrm{~L}$ & n.d. \\
\hline 25 & 66 & M & SP & TxN1Mx & III & 1500 & $\mathrm{~L}$ & 2.0 \\
\hline 26 & 52 & $\mathrm{M}$ & SP & TxN1Mx & III & 1831 & $\mathrm{~L}$ & 1.4 \\
\hline 27 & 42 & M & SP & TxN1Mx & IV & 9227 & $\mathrm{~L}$ & 4.3 \\
\hline
\end{tabular}

Notes: Demographic details (age and sex), inheritance (SP: sporadic; MEN2A: patients with MEN2A RET mutation), TNM classification, staging, plasma CALC levels, lesion type ( $\mathrm{P}$ - primary, $\mathrm{L}$ - lymph node metastases) and maximal tumour diameter. Patients \#1-8 suffered from $\mathrm{CCH}$; patients \#9-27 suffered from MTC. 


\subsection{Materials}

All reagents, if not otherwise specified, were purchased from Sigma-Aldrich (Milano, Italy).

\subsection{TT cell line}

The TT cell line was obtained from the American Type Culture Collection (Manassas, VA, USA) and maintained in culture in F-12 Ham's medium (F-12) and $10 \%$ fetal bovine serum (FBS), as described [24]. TT cells express and secrete CALC, carcinoembryonic antigen, chromogranin A, and other peptides. TT cells harbour a MEN 2A-type mutation, with a cysteine-totryptophan substitution at the level of RET codon 634, and a RET polymorphism glycine-to-serine at codon 691 in exon 11.

\subsection{RNA isolation}

Total RNA was isolated from pulverized tissues and from subconfluent TT cells by Trizol reagent (Invitrogen, Milano, Italy), according to the manufacturer's protocol. To prevent DNA contamination, RNA was treated with RNAse-free deoxyribonuclease (Promega, Milano, Italy). RNA quality and quantity were assessed with the Experion automated electrophoresis system using the Experion RNA StdSens analysis kit (Bio-Rad, Hercules, CA, USA).

\subsection{Qualitative RT-PCR}

Reverse transcription reaction was performed as previously described [28]. Briefly, cDNA (1 $\mu$ l of RT reaction) was amplified by PCR with 1 U Taq DNA polymerase (Invitrogen). PCR reactions for glyceraldehyde-3-phosphate dehydrogenase $(G A P D H)$ and $C A L C$ were carried out as previously described [26]. PCR primers for Thyroglobulin were as follows: forward $5^{\prime}$-TGGATGGAAACAACCCTAGCT-3'; reverse $5^{\prime}$-TCCCACGTAAGATGTAACCCA- $3^{\prime}$. PCR primers for PTTG 1 were as follows: forward $5^{\prime}$-CCCGTGTGG TTGCTAAGGAT- $3^{\prime}$; reverse $5^{\prime}$-GTCACAGCAAA CAGGTGGCA- $3^{\prime}$. Both amplifications were carried out for 40 cycles with the following conditions: denaturation for $30 \mathrm{~s}$ at $95^{\circ} \mathrm{C}$; annealing for $1 \mathrm{~min}$ at $65^{\circ} \mathrm{C}$ and $45 \mathrm{~s}$ at $57^{\circ} \mathrm{C}$; extension for $2 \mathrm{~min}$ at $72^{\circ} \mathrm{C}$ and for $45 \mathrm{~s}$ at $74^{\circ} \mathrm{C}$, respectively.

\subsection{Northern blotting}

To evaluate PTTG1 gene expression in $\mathrm{CCH}, \mathrm{MTC}$, PTC and normal thyroid samples, Northern blot analysis was performed as described [26]. Briefly, probes were obtained by labeling fragments derived from CALC (UniProtKB database Accession P01258) $P T T G 1$ and $G A P D H$. Results are expressed as the ratio between PTTG1 and GAPDH signal intensities. Experiments were performed with at least 3 replicates and results expressed as mean $\pm \mathrm{SE}$.

\subsection{Protein isolation and Western blot analysis}

PTTG Western blot analyses were performed as described previously $[6,20]$. Membranes were blotted overnight with anti-PTTG1 antibody $(2 \mu \mathrm{g} / \mathrm{ml})$ (sc56207; Santa Cruz Biotechnology, Santa Cruz, CA, USA) and with GAPDH antibody ( $1 \mu \mathrm{g} / \mathrm{ml})$. Quantification of bands was carried out using the QuantityOne software (Bio-Rad). Data are expressed as the ratio between PTTG1 and GAPDH signal intensity. Experiments were performed with 3 replicates and results expressed as mean $\pm \mathrm{SE}$.

\subsection{PTTG1 silencing}

For gene silencing, 3 different anti-PTTG1 (gene bank accession no. NM_004219) siRNAs, pre-designed and synthesized by Ambion (St. Austin, TX, USA) were transfected into TT cells by nucleofection. The ID number and targeted sequences are as follows: 289470 (PTTG1 siRNA \#1) - Sense 5'-UCCAAUCUGUUGC AGUCUCtt-3', Antisense: 5'-GAGACUGCAACAGA UUGGAtt-3'; 41990 (PTTG1 siRNA \#2) - Sense 5' GUCUGUAAAGACCAAGGGAtt- $3^{\prime}$, Antisense: $5^{\prime}$ UCCCUUGGUCUUUACAGACtt-3'; 42068 (PTTG1 siRNA \#3) - Sense 5'-GAGUUUGUGUGUGUAUU UGUAtt- $3^{\prime}$, Antisense: $5^{\prime}$ - UACAAAUACACACAAA CUCtg $-3^{\prime}$. Positive controls were employed for gene specificity and for optimizing siRNA experiment (GAPDH siRNA; Ambion, ID: AM4624). Non-targeting control siRNA (Scramble siRNA; Ambion, ID: AM4644) was used for non-specific gene silencing. For evaluation and optimization of transfection efficiency $1.5 \mu \mathrm{g}$ pmaxGFP plasmid (Amaxa, Cologne, Germany) was used for each nucleofection, performed using the cell line optimization Nucleofector Kit (Amaxa) following the manufacturer's protocol. The same conditions were used for siRNA transfections, by using, in total, $100 \mathrm{nM}$ siRNA in TT cells serum- 
starved for $48 \mathrm{~h}$. After optimized nucleofection, cells were immediately transferred to six-well plates, in pre-warmed RPMI medium with 10\% FBS, and incubated for at least $24 \mathrm{~h}$, prior to further experiments. Cells, total RNA, and cell lysates were collected for immunofluorescence, real-time PCR and Western blot studies to determine PTTG1 expression levels.

\subsection{Quantitative PCR for human PTTG}

To evaluate PTTG1 silencing by siRNAs in TT cells, relative quantitative PCR (RQPCR) and Comparative $\mathrm{C}_{\mathrm{T}}$ Method (User Bulletin no. 2, Applied Biosystems) with the predeveloped Taqman Assay Reagent (no. 4331182) were performed by using Assay on Demand Hs00851754_u1 (Applied Biosystems) and hu$\mathrm{PO}$ as reference gene, as previously described [27,28].

To demonstrate specificity of our gene silencing strategy, we also evaluated CALC gene expression by RQPCR, as described above, by using Assay on Demand Hs00266142_m1 (Applied Biosystems).

RQPCR reactions were performed, recorded and analysed using the ABI 7700 Prism Sequence Detection System with the SDS software 1.9 (Applied Biosystems). Samples were carried out in triplicate (50 ng reverse transcribed total RNA per well) and repeated at least twice. Controls without template or RT were run in each experiment.

\subsection{Fluorescence microscopy}

To evaluate securin expression in control, PTTG1 silenced TT cells, $2 \times 10^{4}$ cells/well were seeded in 8 well chamber slides (Lab-Tek Chamber Slide System, Nalgene Nunc International, Naperville, IL, USA) and incubated $30 \mathrm{~min}$ in a humified atmosphere at $37^{\circ} \mathrm{C}$ with a mouse monoclonal anti human PTTG1 antibody $(3.5 \mu \mathrm{g} / \mathrm{ml}$ ) (Zymed Laboratories). Cells were fixed in methanol-acetone $(1: 1)$ for $10 \mathrm{~min}$ at $-20^{\circ} \mathrm{C}$, blocked for $1 \mathrm{~h}$ with blocking buffer (5\% goat serum in PBS), and incubated with a secondary fluorescein isothiocyanate (FITC)-conjugated goat anti mouse antibody (1:200; Invitrogen Molecular Probes, Eugene, OR, USA) for $45 \mathrm{~min}$ at room temperature. Slides were mounted with the ProLong Gold antifade reagent (Invitrogen Molecular Probes) containing the nuclear stain $4^{\prime}, 6^{\prime}$-diamidino-2-phenylindole (DAPI) under glass coverslips (Menzel-Glaser, Braunschweig, Germany). Slides were visualized with a Nikon Eclipse TE2000-U fluorescent microscope, photographed with a $\times 20$ or $\times 60$ objective magnification with a DS-5M
Nikon colour CCD digital camera and analyzed with the Multi-Analyst software (Bio-Rad). Pre-immune serum and antigen-absorbed antibody were used as controls. All experiments were carried out independently at least three times and $50 \pm 10$ individual cells analysed.

\subsection{DNA synthesis}

To investigate the effects of PTTG1 silencing on DNA synthesis, $\left[{ }^{3} \mathrm{H}\right]$ Thymidine $\left(\left[{ }^{3} \mathrm{H}\right]\right.$ Thy) incorporation was measured in control, and in PTTG1 silenced cells, as described [25]. Cells were incubated in Ham's F-12 medium without serum for $36 \mathrm{~h}$, and then cultured in Ham's F-12 medium supplemented with $10 \%$ FBS for up to $72 \mathrm{~h}$ in the presence of $\left[{ }^{3} \mathrm{H}\right]$ Thy $(1.5 \mu \mathrm{Ci} / \mathrm{ml}$; $87 \mathrm{Ci} / \mathrm{mmol}$, Amersham-Pharmacia Biotech Italia, Cologno Monzese, Italy) for the last $24 \mathrm{~h}$ before harvesting the cells. After incubation, cell-associated radioactivity was determined after harvesting cells on glass fibers, and liquid scintillation counting in at least three separate experiments. Results are calculated as average counts per minute of quadruplicate wells \pm SE.

\subsection{Statistical analysis}

Data are expressed as mean \pm SE. A preliminary analysis was carried out to determine whether the data sets conformed to a normal distribution, and a computation of homogeneity of variance was performed using Bartlett's test. Results were compared within each group and between groups using ANOVA. If $F$ values were significant $(p<0.05)$, Student's paired or unpaired $t$-test was used to evaluate individual differences between means. To measure the strength of association between pairs of variables without specifying dependencies, Spearman order correlations were run. $p<0.05$ was considered significant in all tests.

\section{Results}

\subsection{PTTG1 mRNA expression in CCH, MTC, PTC and normal thyroid tissue}

Northern blot analysis showed that PTTG1 mRNA expression was significantly higher in $\mathrm{CCH}$ (3-fold), in PTC and in MTC samples (5-fold) than in normal thyroid (NT) specimens (Fig. $1 ; p<0.01$ ). PTTG1 mRNA expression was higher in MTC as compared to 


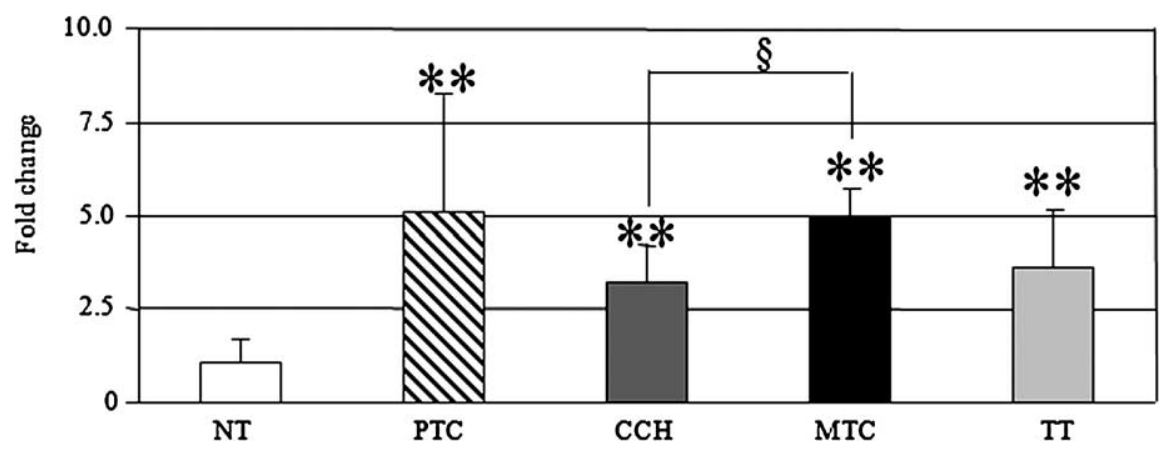

(A)

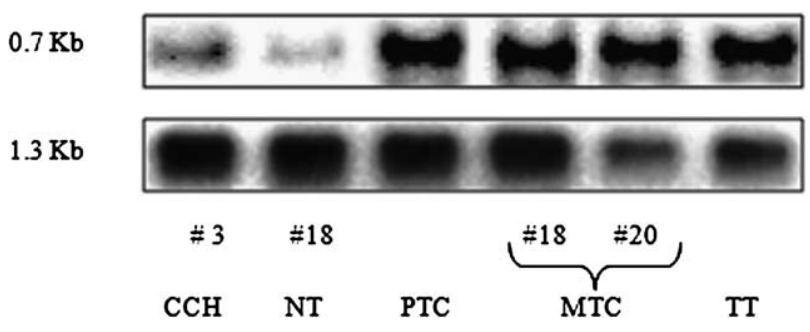

PTTGI

(B)

Fig. 1. Northern blot analysis of PTTG1 gene expression. (A) Northern blot analysis for PTTG1 mRNA expression in normal thyroid tissue (NT), $4 \mathrm{PTC}, 8 \mathrm{CCH}, 19 \mathrm{MTC}$ and TT cells, expressed as fold changes vs. NT $\pm \mathrm{SE} .{ }^{* *} p<0.01, P T T G 1 \mathrm{mRNA}$ expression vs. NT; ${ }^{\S} p<0.05, P T T G 1$ mRNA expression in CCH vs. MTC. NT - normal thyroid; PTC - papillary thyroid carcinoma; CCH - C-cell hyperplasia; MTC - medullary thyroid carcinoma; TT - TT cell line. (B) PTTG1 mRNA levels. Representative Northern blot analysis for PTTG1 and GAPDH expression in C-cell hyperplasia $(\mathrm{CCH})$, normal thyroid (NT), papillary thyroid carcinoma (PTC), medullary thyroid carcinoma (MTC) samples and TT cells. Depicted results are representative of at least 3 different experiments.

$\mathrm{CCH}(p<0.05)$, and 2-fold higher in MTC lymphnode metastases as compared to primary thyroid lesions (Fig. 2A; $p<0.05$ ). Regression analysis showed a positive correlation between TNM status and PTTG1 mRNA expression in $\mathrm{CCH}$ and MTC samples $(p<$ 0.05). Similarly, PTTG1 mRNA expression in 12 MTC samples derived from primary thyroid lesions correlated with tumour diameter $\left(r^{2}=0.693 ; p<0.01\right)$ (Fig. 2B).

\subsection{PTTG1 protein levels in CCH and MTC}

Western blot analysis of $\mathrm{CCH}$ and MTC protein extracts confirmed the mRNA results, since PTTG1 protein expression was greater in tumour samples as compared to normal thyroid tissue, and in MTC as compared to $\mathrm{CCH}$ (Fig. 2C). Regression analysis evaluating tumour diameter and PTTG1 protein levels in MTC samples demonstrated a correlation between these two parameters $\left(r^{2}=0.7981 ; p<0.001\right)$ (Fig. 2D).

\subsection{Evaluation of PTTG1 gene silencing}

For PTTG1 silencing, we used three different siRNA, derived from various regions of the PTTG1 coding sequence; a transfection efficiency of about $80 \%$ was achieved (data not shown). The extent of PTTG1 gene silencing was evaluated by RQPCR in TT cells $72 \mathrm{~h}$ after transfection. A substantial and consistent reduction in PTTG1 mRNA levels was observed after transfection with PTTG1 siRNAs \#1 and \#3 as compared to untransfected control cells (18\% and $36 \%$ PTTG expression relative to control cells, respectively; $p<0.01$ ) (Fig. 3A). siRNA transfection determined a specific PTTG1 mRNA suppression as shown by a non significant reduction in PTTG1 expression in TT cells transfected with GAPDH siRNA or with scramble siRNA. Further confirmation of gene silencing specificity was provided by the evidence that GAPDH mRNA was significantly reduced in TT cells transfected with GAPDH siRNA but not in PTTG1 silenced cells (data not shown). We therefore selected PTTG1 siRNA \#1 and \#3 for further experiments. To further confirm the specificity of our gene silencing approach, CALC mRNA levels were measured by RQPCR in control untransfected TT cells, as well as in TT cells transfected with scramble siRNA, GAPDH siRNA, or with PTTG1 siRNAs \#1 or \#3. 


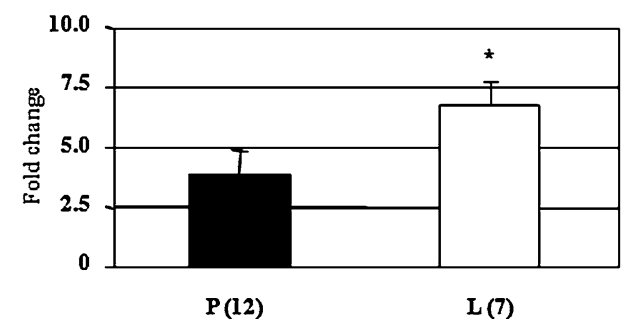

(A)

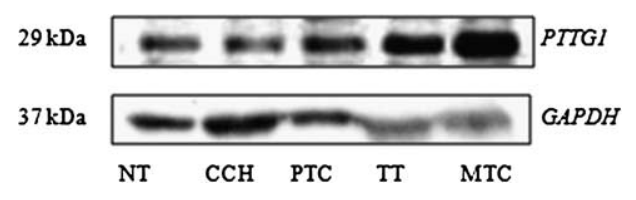

(C)

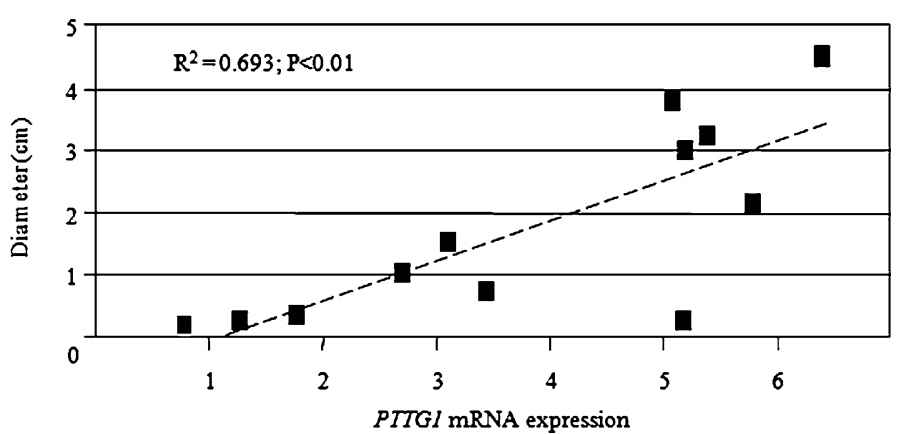

(B)

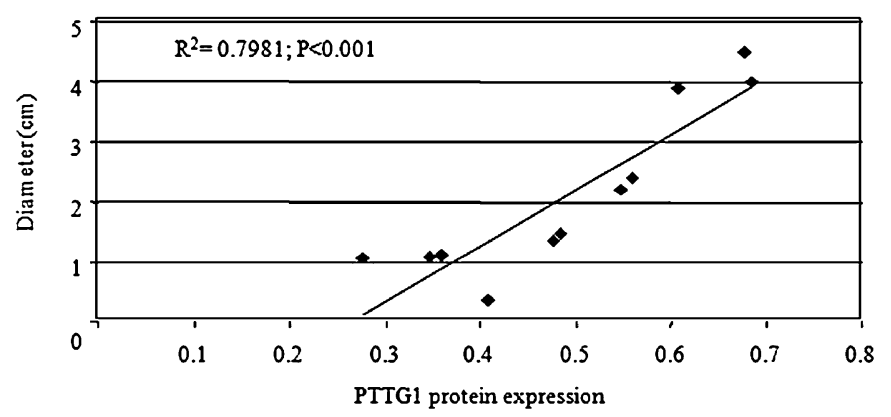

(D)

Fig. 2. PTTG1 mRNA and protein expression in human MTC. (A) Mean PTTG1 mRNA expression in 12 MTC primary thyroid lesions (P) and in 7 MTC lymph node metastases (L) expressed as fold change vs. normal thyroid tissue $\pm \mathrm{SE} .{ }^{*} p<0.05$ PTTG1 mRNA expression in L vs. P. (B) Correlation between MTC tumour diameter $(\mathrm{cm})$ and PTTG1 mRNA expression (Arbitrary units). (C) PTTG1 protein levels. Representative Western blot analysis for PTTG1 and GAPDH protein expression in normal thyroid (NT), C-cell hyperplasia (CCH), papillary thyroid carcinoma (PTC), TT cells and in medullary thyroid carcinoma (MTC) samples. Whole cell extracts ( $80 \mu \mathrm{g}$ ) from each sample were fractionated on $12.5 \%$ SDS-PAGE, transferred on nitrocellulose membrane and incubated with an anti-PTTG1 antibody and, after stripping, with an anti-GAPDH antibody. (D) Correlation between MTC tumour diameter $(\mathrm{cm})$ and PTTG1 protein levels (Arbitrary units).

Figure 3B shows that $C A L C$ mRNA levels were comparable in all tested samples, indicating that PTTG1 gene silencing did not influence expression of other genes.

To evaluate whether reduced PTTGl mRNA after PTTG1 gene silencing corresponded to decreased PTTG1 protein levels, we performed immunofluorescence studies in control untransfected TT cells and in TT cells transfected with scramble siRNA, GAPDH siRNA, or with PTTG1 siRNAs \#1 and \#3. Seventy two hours after transfection, cells were incubated with a specific PTTG1 antibody, fixed, incubated with secondary FITC-conjugated antibody, and observed for specific immunofluorescence. As shown in Fig. 4, PTTG1 immunofluorescence was clearly visible in control untransfected TT cells. Transfection with scramble siRNA did not affect $P T T G 1$ protein expression, while in cells transfected with PTTG1 siRNA \#1 or \#3 specific PTTG1 immunofluorescence was greatly reduced.

\subsection{Effect of PTTG1 silencing on $\left[{ }^{3} H\right] T h y$ incorporation in TT cells}

To test the effects of PTTG1 silencing on TT cell proliferation, we evaluated DNA synthesis by measuring $\left[{ }^{3} \mathrm{H}\right]$ Thy incorporation for up to $72 \mathrm{~h}$ after gene silencing. Figure 5A shows that transfection with PTTG1 siRNA \#1 and \#3 resulted in reduced $\left[{ }^{3} \mathrm{H}\right]$ Thy incorporation at $72 \mathrm{~h}$, as compared to TT cells transfected with GAPDH siRNA $(-47 \%$ and $-51 \%$, respectively; $p<0.01)$. Transfected cells continued incorporating $\left[{ }^{3} \mathrm{H}\right]$ Thy, indicating that DNA synthesis was not completely blocked. DNA synthesis in TT cells transfected with scramble siRNA or with $G A P D H$ siRNA was similar to that observed in untransfected control TT cells. These results indicate that the observed effects on cell proliferation depend on specific gene silencing (i.e., PTTG1 down-regulation) and not on the transfection procedure per se. 


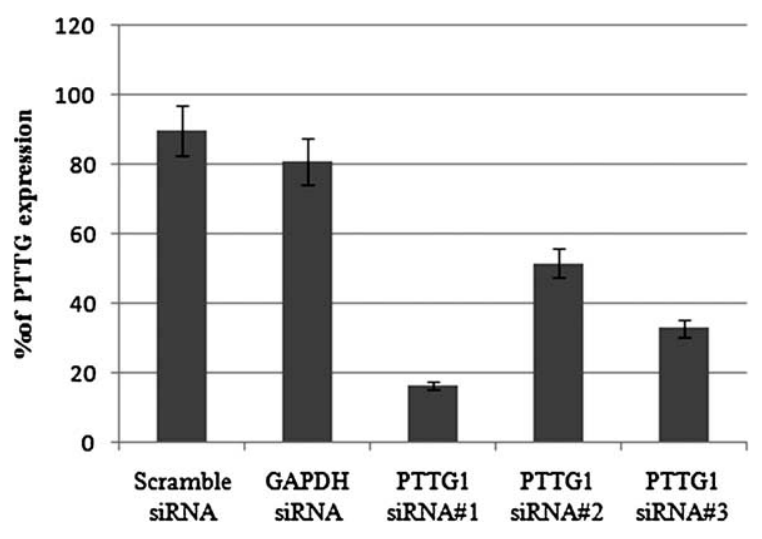

(A)

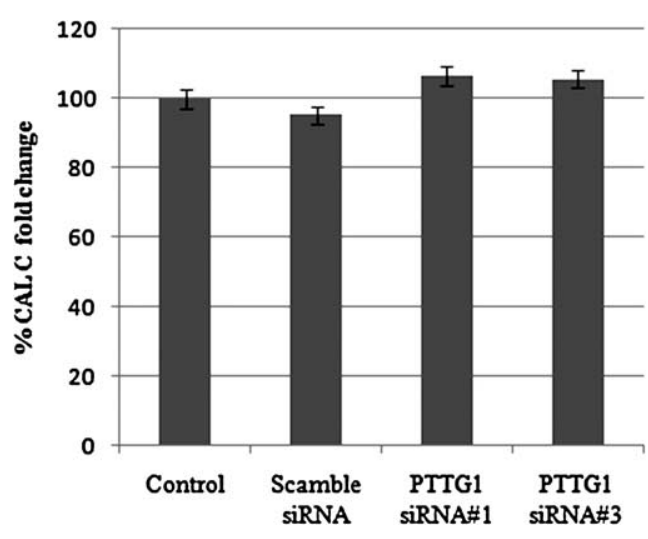

(B)

Fig. 3. RQ-PCR evaluating the effect of gene silencing on PTTG1 and CALC mRNA expression in TT cells. (A) TT cells were transfected with scramble siRNA, GAPDH siRNA, or with PTTG1 siRNA \#1, \#2 and \#3. After $72 \mathrm{~h}$, cells were harvested and used for RNA isolation. One $\mu \mathrm{g}$ RNA was reverse-transcribed and RQ-PCR performed to evaluate PTTG1 mRNA expression. Data are shown as percentage of PTTG1 expression in transfected TT cells as compared to control untransfected TT cells (100\%), and represent the mean value \pm SE of at least three independent experiments. ${ }^{* *} p<0.01$ vs. control untransfected TT cells. (B) TT cells were transfected with scramble siRNA, GAPDH siRNA, or with PTTG1 siRNA \#1 and \#3. After $72 \mathrm{~h}$, cells were harvested and submitted to RNA isolation. One $\mu \mathrm{g}$ of RNA was reverse-transcribed and RQ-PCR performed to evaluate $C A L C$ mRNA expression. Data are shown as percentage vs. CALC expression in TT cells transfected with GAPDH siRNA, PTTG1 siRNA \#1-3 as compared to untransfected TT cells and represent the mean value \pm SE of at least three independent experiments.

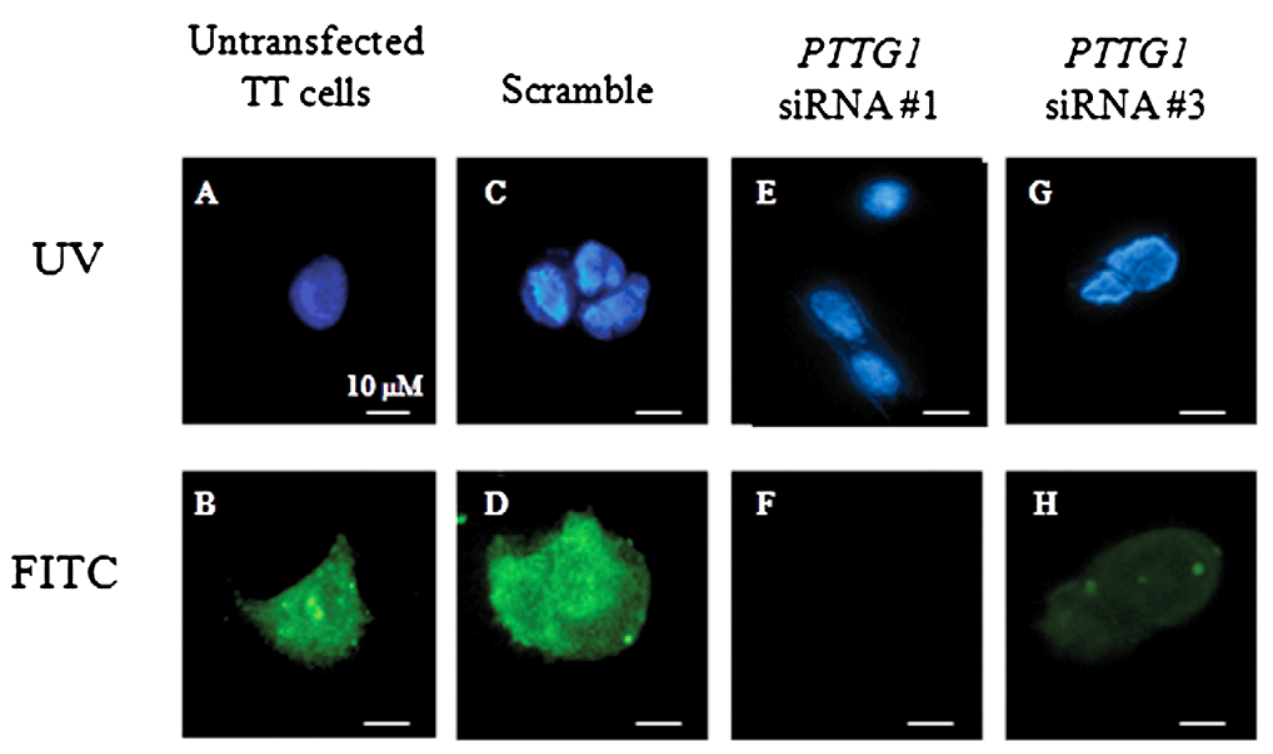

Fig. 4. PTTG1 protein expression. TT cells were transfected with scramble siRNA, or with PTTG1 siRNA \#1 and \#3 and fixed 48 h after transfection. Untransfected and transfected TT cells were incubated with the specific PTTG1 antibody, fixed, incubated with the secondary FITC-conjugated antibody, mounted with the antifade reagent containing DAPI, and photographed with a $60 \times$ objective magnification. Cells were observed with the FITC filter, revealing specific PTTG1 immunofluorescence, and with the UV filter, revealing nuclear fluorescence. Figures are representative of at least three experiments.

\section{Discussion}

Human PTTG1, originally isolated from rat prolactin-secreting cells and encoded by a gene located on chromosome 5 [22], play a role in tumour initiation and progression [29]. PTTG1 mRNA levels are increased in human thyroid tumours, compared with normal thyroid tissue. Increased PTTG1 expression was detected early in thyroid tumour development, progressively increasing in thyroid hyperplasia, follicular ade- 


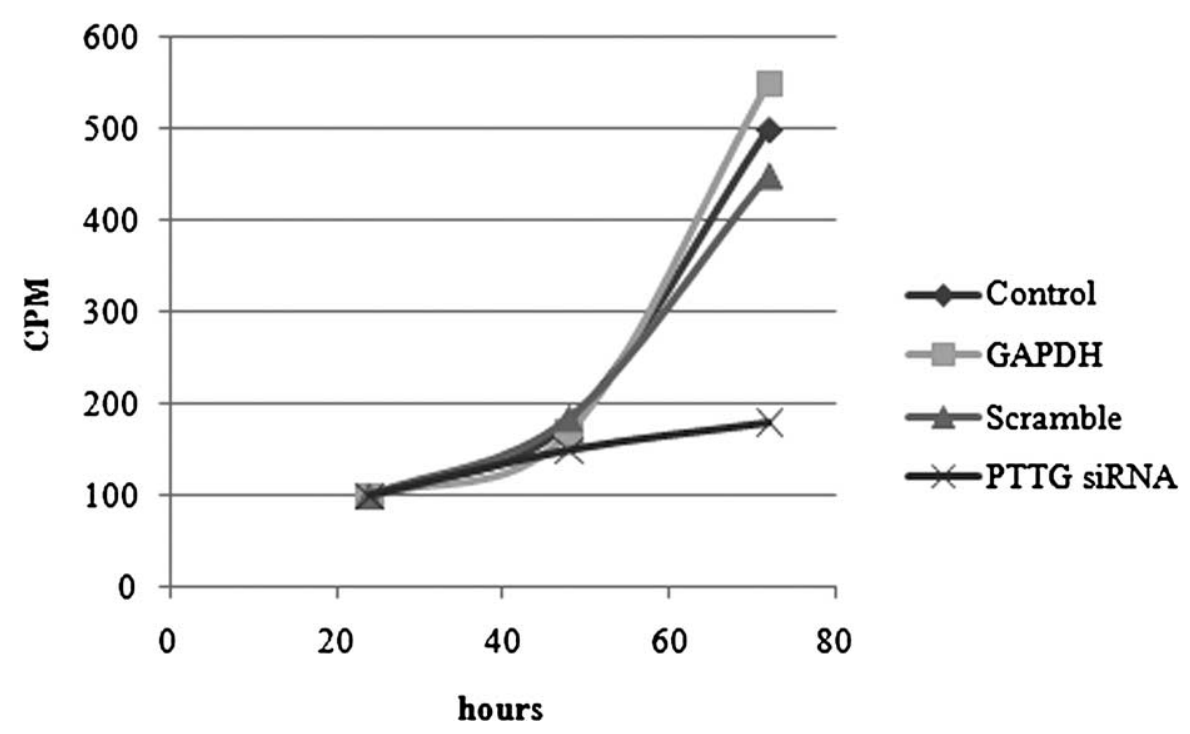

Fig. 5. Effect of PTTG1 silencing on $\left[{ }^{3} \mathrm{H}\right]$ Thy incorporation in TT cells. Panel A: TT cells were transfected with PTTG1 siRNA \#1 and \#3, positive control GAPDH siRNA or negative control scramble siRNA, and cultured for up to $72 \mathrm{~h}$. DNA synthesis was evaluated by measuring $\left[{ }^{3} \mathrm{H}\right]$ Thy incorporation (cpm) in at least 3 independent experiments in transfected and in control untransfected cells (Control) after 48 and $72 \mathrm{~h}$. Results were calculated as average counts per minute of quadruplicate wells $\pm \mathrm{SE}$.

nomas, papillary cancer and follicular carcinomas [7]. PTTG1 overexpression was associated with the presence of nodal or distant metastases, TNM stage and decreased radioiodine uptake during follow-up, suggesting that PTTG1 expression might represent an independent prognostic factor for persistent disease in the settings of papillary and follicular thyroid cancer [3]. However, to our knowledge, this is the first study investigating the role of PTTG1 expression in human MTC. To study the role of PTTG1 in parafollicular C-cell neoplastic transformation, we explored the hypothesis that PTTG1 expression in human $\mathrm{CCH}$ and $\mathrm{MTC}$ is a useful marker of cancer behavior. Indeed, we found that PTTG1 expression increases with disease progression, as also underscored by the correlation with primary lesion diameter and with TNM stage at presentation. Moreover, PTTG1 expression was higher in human $\mathrm{CCH}$ and MTC as compared to normal thyroid tissue. This finding might also be due to the fact that $\mathrm{CCH}$ and MTC are composed by C-cells, while normal thyroid samples are mainly comprised of follicular thyroid cells. Evaluation of normal C-cell gene expression is hampered by the fact that they represent only a minority of the normal thyroid gland cell population. On the other hand, we found most abundant PTTG1 expression in MTC as compared to $\mathrm{CCH}$, which represents a widely accepted pre-malignant step in C-cell neoplastic transformation [12]. These results are in accordance with the putative role of PTTG1 in C-cell neoplastic modification, suggesting that PTTG1 overexpression associates with disease progression, as demonstrated in other endocrine tumours [19]. However, since the number of examined samples is low due to the rarity of the disease, to clarify this issue further evidence was sought in a cell line model.

To verify whether PTTG1 influences C-cell neoplastic proliferation, we explored the effects of PTTG1 gene silencing in human MTC cells, the TT cell line. We demonstrate that TT cells are a reliable model to investigate PTTG1 activity, since this cell line expresses the gene at high levels, similar to those found in human MTC.

Our results show that gene silencing effectively down regulates PTTG1 expression, without influencing the expression of other C-cell specific genes, such as CALC. Therefore, modifications in TT cell parameters after PTTG1 silencing appear to be specific.

Our results show that specific PTTGl silencing induces a significant reduction in DNA synthesis, and reduced cell proliferation rates persist for at least 3 days, indicating that PTTG1 expression down-regulation slows TT cell proliferation. This evidence supports the hypothesis that PTTG1 plays an important role in C-cell neoplastic proliferation, suggesting a proliferative requirement for this gene in MTC development. Indeed, when considered as an oncogenic protein, PTTG1 is expected to have pro-proliferative effects, as also indicated by others [9]. On the other hand, 
as a securin protein which normally inhibits cell division, high PTTG1 expression levels would be expected to inhibit cell proliferation, as demonstrated by $\mathrm{Yu}$ et al. [23]. It has been previously suggested that the stimulatory/inhibitory role of PTTG upon cell proliferation may be regulated by PTTG1 phosphorylation status, by PTTG1 specific ability to degrade exogenous PTTG1, or may be dose-dependent [17]. Moreover, it has been previously demonstrated that transfection of FTC133 cells with PTTG1 dose-dependently increased genetic instability [10]. A high degree of genetic instability is also related to a reduced tumour growth potential, since it targets tumour cells to death [2]. Our results are in line with the hypothesis that PTTG acts as an oncogene in C-cells.

In conclusion, our work provides evidence for an important role of PTTG1 in MTC cell proliferation.

\section{Acknowledgements}

This work was supported by grants from the Italian Ministry of Education, University and Research to the University of Ferrara, Fondazione Cassa di Risparmio di Ferrara, Associazione Italiana per la Ricerca sul Cancro, Associazione Ferrarese dell'Ipertensione Arteriosa, and progetto Regione-Università of the Regione Emilia-Romagna.

\section{References}

[1] K. Akino, S. Akita, T. Mizuguchi, I. Takumi, R. Yu, X.Y. Wang, J. Rozga, A.A. Demetriou, S. Melmed, A. Ohtsuru and S. Yamashita, A novel molecular marker of pituitary tumour transforming gene involves in a rat liver regeneration, Journal of Surgical Research 129 (2005), 142-146.

[2] S.E. Artandi and R. DePinho, Telomeres and telomerase in cancer, Carcinogenesis 31 (2010), 9-18.

[3] K. Boelaert, C.J. McCabe, L.A. Tannahill, N.J. Gittoes, R.L. Holder, J.C. Watkinson, A.R. Bradwell, M.C. Sheppard and J.A. Franklyn, Pituitary tumour transforming gene and fibroblast growth factor-2 expression: potential prognostic indicators in differentiated thyroid cancer, Journal of Clinical Endocrinology and Metabolism 88 (2003), 2341-2347.

[4] K. Boelaert, L.A. Tannahill, J.N. Bulmer, S. Kachilele, S.Y. Chan, D. Kim, N.J. Gittoes, J.A. Franklyn, M.D. Kilby and C.J. McCabe, A potential role for PTTG/securin in the developing human fetal brain, FASEB Journal 17 (2003), 1631-1639.

[5] A. Cascon, A. Cebrian, M. Pollan, S. Ruiz-Llorente, C. Montero-Conde, R. Leton, R. Gutierrez, F. Lesueur, R.L. Milne, O. Gonzalez-Albarran, T. Lucas-Morante, J. Benitez, B.A. Ponder and M. Robledo, Succinate dehydrogenase D variants do not constitute a risk factor for developing $\mathrm{C}$ cell hyperplasia or sporadic medullary thyroid carcinoma, Journal of Clinical Endocrinology and Metabolism 90 (2005), 21272130 .
[6] E. Giorda, L. Sibilio, A. Martayan, G. Feriotto, N. Bianchi, C. Mischiati, F. Di Rosa, L. Pozzi, R. Gambari and P. Giacomini, Modular usage of the HLA-DRA promoter in extrahematopoietic and hematopoietic cell types of transgenic mice, FEBS Journal 272 (2005), 3214-3226.

[7] A.P. Heaney, V. Nelson, M. Fernando and G. Horwitz, Transforming events in thyroid tumourigenesis and their association with follicular lesions, Journal of Clinical Endocrinology and Metabolism 86 (2001), 5025-5032.

[8] H. Ishikawa, A.P. Heaney, R. Yu, G.A. Horwitz and S. Melmed, Human pituitary tumour-transforming gene induces angiogenesis, Journal of Clinical Endocrinology and Metabolism 86 (2001), 867-874.

[9] S. Kakar and M.T. Malik, Suppression of lung cancer with siRNA targeting PTTG, International Journal of Oncology 29 (2006), 387-395.

[10] D. Kim, H. Pemberton, A.L. Stratford, K. Boelaert, J.C. Watkinson, V. Lopes, J.A. Franklyn and C.J. McCabe, Pituitary tumour transforming gene (PTTG) induces genetic instability in thyroid cells, Oncogene 24 (2005), 4861-4866.

[11] C.A. Koch, F.M. Brouwers, A.O. Vortmeyer, A. Tannapfel, S.K. Libutti, Z. Zhuang, K. Pacak, H.P. Neumann and R. Paschke, Somatic VHL gene alterations in MEN2associated medullary thyroid carcinoma, BMC Cancer 6 (2006), 131.

[12] A. Machens, P. Niccoli-Sire, J. Hoegel, K. Frank-Raue, T.J. Van Vroonhoven, H.D. Roeher, R.A. Wahl, P. Lamesch, F. Raue, B. Conte-Devolx and H. Dralle, European Multiple Endocrine Neoplasia (EUROMEN) Study Group. Early malignant progression of hereditary medullary thyroid cancer, New England Journal of Medicine 349 (2003), 1517-1525.

[13] C.J. McCabe, V. Boelaert, L.A. Tannahill, A.P. Heaney, A.L. Stratford, J.S. Khaira, S. Hussain, M.C. Sheppard, J.A. Franklyn and N.J. Gittoes, Vascular endothelial growth factor, its receptor KDR/Flk-1, and pituitary tumour transforming gene in pituitary tumours, Journal of Clinical Endocrinology and Metabolism 87 (2002), 4238-4244.

[14] L. Pei, Activation of mitogen-activated protein kinase cascade regulates pituitary tumour-transforming gene transactivation function, Journal of Biological Chemistry 275 (2000), 3119131198.

[15] L. Pei and S. Melmed, Isolation and characterization of a pituitary tumour-transforming gene (PTTG), Molecular Endocrinology 11 (1997), 433-441.

[16] F. Romero, M.C. Multon, F. Ramos-Morales, A. Dominguez, J.A. Bernal, J.A. Pintor-Toro and M. Tortolero, Human securin, hPTTG, is associated with Ku heterodimer, the regulatory subunit of the DNA-dependent protein kinase, Nucleic Acids Research 29 (2001), 1300-1307.

[17] F. Salehi, K. Kovacs, B.W. Scheithauer, R.V. Lloyd and M. Cusimano, Pituitary tumour-transforming gene in endocrine and other neoplasms: a review and update, Endocrine Related Cancer 15 (2008), 721-743.

[18] M. Santoro, R.M. Melillo, F. Carlomagno, R. Visconti, G. De Vita, G. Salvatore, G. Lupoli, A. Fusco and G. Vecchio, Molecular biology of the MEN2 gene, Journal of Internal Medicine 243 (1998), 505-508.

[19] A.L. Stratford, K. Boelaert, L.A. Tannahill, D.S. Kim, A. Warfield, M.C. Eggo, N.J. Gittoes, L.S. Young, J.A. Franklyn and C.J. McCabe, Pituitary tumour transforming gene binding factor: a novel transforming gene in thy- 
roid tumourigenesis, Journal of Clinical Endocrinology and Metabolism 90 (2005), 4341-4349.

[20] F. Tagliati, M.C. Zatelli, A. Bottoni, D. Piccin, A. Luchin, M.D. Culler and E.C. degli Uberti, Role of complex cyclin $\mathrm{d} 1 / \mathrm{cdk} 4$ in somatostatin subtype 2 receptor-mediated inhibition of cell proliferation of a medullary thyroid carcinoma cell line in vitro, Endocrinology 147 (2006), 3530-3538.

[21] Y. Tong, Y. Tan, C. Zhou and S. Melmed, Pituitary tumour transforming gene interacts with $\mathrm{Sp} 1$ to modulate G1/S cell phase transition, Oncogene 26 (2007), 5596-5605.

[22] G. Vlotides, T. Eigler and S. Melmed, Pituitary tumourtransforming gene: physiology and implications for tumourigenesis, Endocrine Reviews 28 (2007), 165-186.

[23] R. Yu, S.G. Ren, G.A. Horwitz, Z. Wang and S. Melmed, Pituitary tumour transforming gene (PTTG) regulates placental JEG-3 cell division and survival: evidence from live cell imaging, Molecular Endocrinology 14 (2000), 1137-1146.

[24] M.C. Zatelli, F. Tagliati, J.E. Taylor, R. Rossi, M.D. Culler and E.C. degli Uberti, Somatostatin receptor subtypes 2 and 5 differentially affect proliferation in vitro of the human medullary thyroid carcinoma cell line TT, Journal of Clinical Endocrinology and Metabolism 86 (2001), 2161-2169.

[25] M.C. Zatelli, F. Tagliati, D. Piccin, J.E. Taylor, M.D. Culler, M. Bondanelli and E.C. degli Uberti, Somatostatin receptor subtype 1-selective activation reduces cell growth and calcitonin secretion in a human medullary thyroid carcinoma cell line, Biochemical Biophysical Research Communications 297 (2002), 828-834.

[26] M.C. Zatelli, F. Tagliati, J.E. Taylor, D. Piccin, M.D. Culler and E.C. degli Uberti, Somatostatin, but not somatostatin receptor subtypes 2 and 5 selective agonists, inhibits calcitonin secretion and gene expression in the human medullary thyroid carcinoma cell line, TT, Hormone \& Metabolic Research 34 (2002), 229-233.

[27] M.C. Zatelli, D. Piccin, A. Bottoni, M.R. Ambrosio, A. Margutti, R. Padovani, M. Scanarini, J.E. Taylor, M.D. Culler, L. Cavazzini and E.C. degli Uberti, Evidence for differential effects of selective somatostatin receptor subtype agonists on alpha-subunit and Chromagranin A secretion and on cell viability in human non functioning pituitary adenomas in vitro, Journal of Clinical Endocrinology and Metabolism 89 (2004), 5181-5188.

[28] M.C. Zatelli, D. Piccin, F. Tagliati, A. Bottoni, A. Luchin, C. Vignali, A. Margutti, M. Bondanelli, G.C. Pansini, M.R. Pelizzo, M.D. Culler and E.C. degli Uberti, Selective activation of somatostatin receptor subtypes differentially modulates secretion and viability in human medullary thyroid carcinoma primary cultures: potential clinical perspectives, Journal of Clinical Endocrinology and Metabolism 91 (2006), 22182224.

[29] X. Zhang, G.A. Horwitz, A.P. Heaney, M. Nakashima, T.R. Prezant, M.D. Bronstein and S. Melmed, Structure, expression, and function of human pituitary tumour-transforming gene (PTTG), Molecular Endocrinology 13 (1999), 156-166.

[30] H. Zou, T.J. McGarry, T. Bernal and M.W. Kirschner, Identification of a vertebrate sister-chromatid separation inhibitor involved in transformation and tumourigenesis, Science $\mathbf{2 8 5}$ (1999), 418-422.

[31] A. Zur and M. Brandeis, Securin degradation is mediated by fzy and fzr, and is required for complete chromatid separation but not for cytokinesis, EMBO Journal 20 (2001), 792-801. 


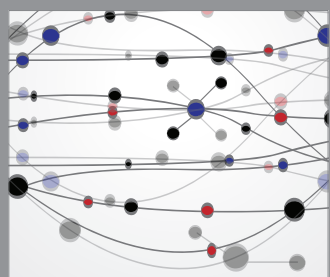

The Scientific World Journal
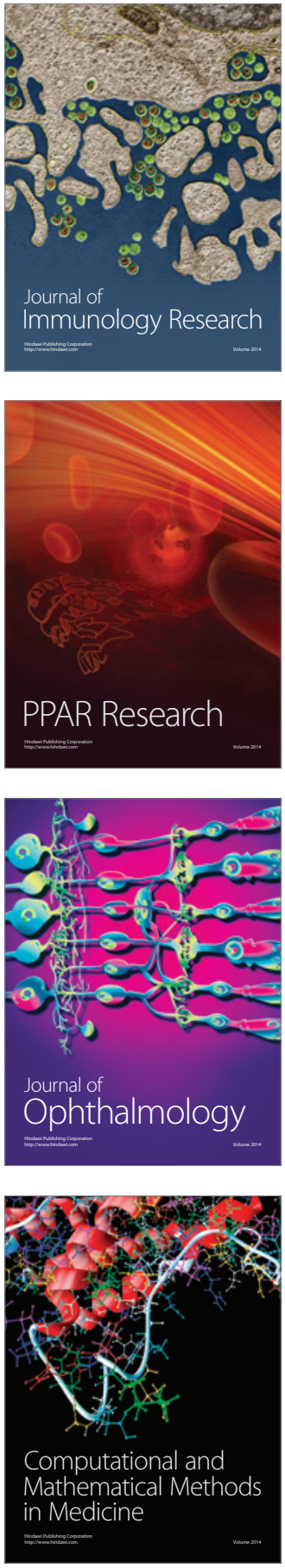

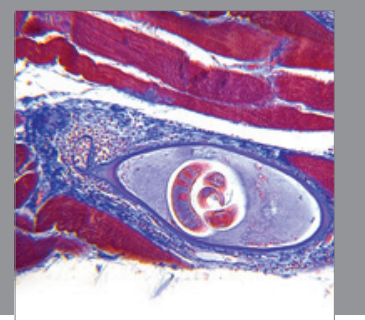

Gastroenterology

Research and Practice
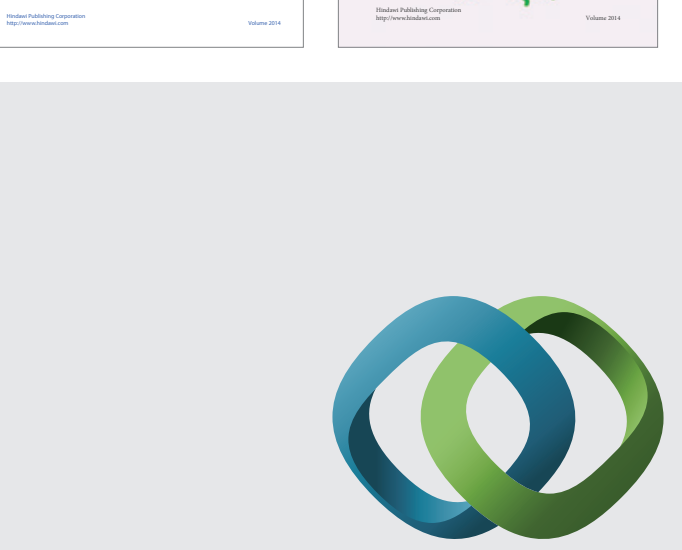

\section{Hindawi}

Submit your manuscripts at

http://www.hindawi.com
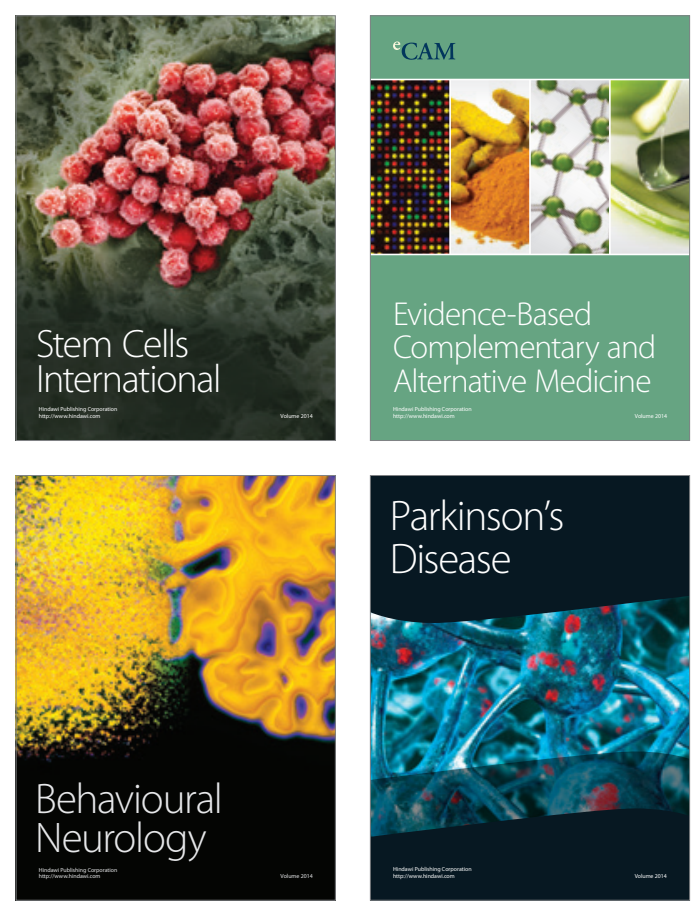

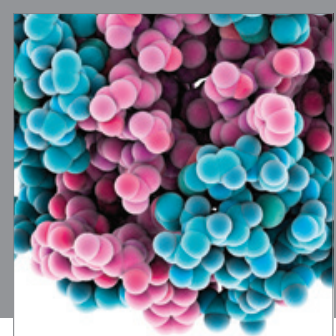

Journal of
Diabetes Research

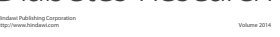

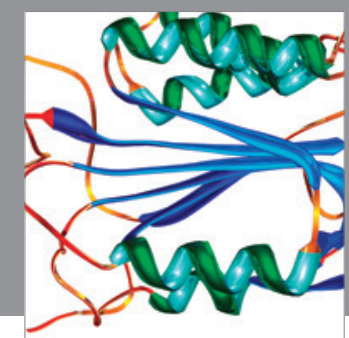

Disease Markers
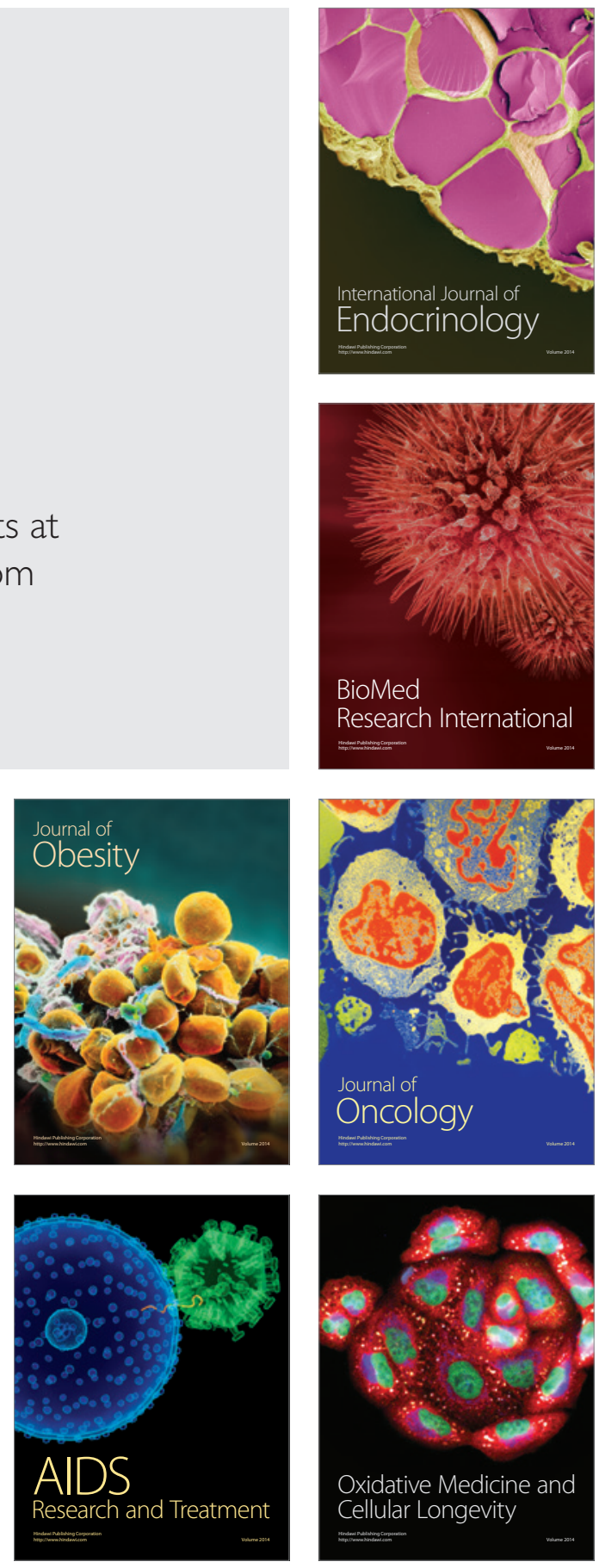